\title{
Green Networking a Way to Increase Recycling
}

\section{Awareness}

\author{
Rabiatu Baba Shehu \\ B.Sc Environmental Health Management, Canadian University Dubai \\ PO Box 117781, Sheikh Zayed Road, Behind the Shangri-La Hotel, Dubai, UAE \\ Tel: 971-544-328-761Ｅ-mail: rabi-bs@hotmail.com
}

\author{
Halima Baba Shehu \\ B.Sc Environmental Health Management, Canadian University Dubai \\ PO Box 117781, Sheikh Zayed Road, Behind the Shangri-La Hotel, Dubai, UAE \\ Tel: 971-544-327-375 E-mail: hally_bs@hotmail.com \\ Rami El Khatib (Corresponding Author) \\ Associate Professor, Department of Environmental Health Sciences \\ Canadian University Dubai, PO Box 117781 \\ Sheikh Zayed Road, Behind the Shangri-La Hotel, Dubai, UAE \\ Tel: 971-4709-6808Ｅ-mail: rami@cud.ac.ae
}

Received: February 7, 2018 Accepted: February 22, 2018 Published: March 15, 2018

doi:10.5296/emsd.v7i2.12614 URL: https://doi.org/10.5296/emsd.v7i2.12614

\begin{abstract}
This paper demonstrates the need to promote recycling as part of individual's lifestyle, it shows the economic consequences of recycling on the global environment, it entails the effects of green networking in today's world and how the lifestyles of individuals from various academic settings are impacted. The findings in this paper reveal how 'green networking' or 'green social media' improves student's behavior towards recycling, it also shows how environmental organizations use green networking as an effective tool for recycling awareness. To attain this information, firstly, an online/ physical 20 questions
\end{abstract}


survey was conducted among 777 students from ages 14-30+ within: (I) high school grades 10-12 and (II) university undergrad/postgrad level. These students were derived from various educational backgrounds ranging from American, British, Arabic and Canadian academic systems across the emirate of Dubai. Secondly, environmental organizations from the public and private companies such as Provectus and Emirates Environmental Group completed an online survey of 8 questions to provide an insight on how green networking can influence recycling, from different products like paper, plastic, cans, food/water, lastly, it provides data on how individuals respond to recycling policies. Finally, it will demonstrate the ways in which multimedia can be used as an economical tool for waste management.

Keywords: Green Social Media, Recycling lifestyle, Economy, Students' Behaviours, Environmental Sustainability

\section{Introduction}

\subsection{Overview of Green Networking \& Recycling in today's World}

In today's world where social media is incorporated in individuals' lifestyles, a population balance and global economic concerns are portrayed through media portals. A major economic issue the world faces is finding a balance between pollution (waste generation) and recycling (waste minimization). Companies, economies, governments and educational/research institutions around the globe are striving to uphold the equilibrium between pollution and recycling through sustainable awareness campaigns/activities, this strategy is done through 'green social media' or 'green networking.' In order to understand the links between green social media, recycling, and pollution one must first define the terminologies. (I) According to Environment Protection Agency, (2016): recycling is defined as "the process of collecting and processing materials that would otherwise be thrown away as trash and turning them into new products" (EPA, 2016). (II) According to Technopedia (2016): green networking or green social media is defined as "Green networking is a broad term referring to processes used to optimize networking or make it more efficient" (Technopedia, 2016).

This term covers the processes that reduce energy consumption, as well as processes for conserving environmental materials or any other process that will ultimately reduce energy use/ financial cost." To further understand the concept of green networking one must analyze the impact of social media in an economical perspective, this is known as 'social media marketing:' a term used to show the evolution of marketing; moving from the traditional sense of publicizing into a modernized era where marketing tools: such as Twitter, Facebook, YouTube etc. are used to promote ecological sustainability, eco-lifestyle and environmental conservation blogging. These social media tools have become centralized in the educational and working industry, the majority of students and workers around the globe utilize social media in their daily activities (Technopedia, 2016).

With global demand for sustainable development one sees the trend of green networking encoded in environmental organizations, governments, academic institution and general businesses; they're adopting such marketing tools to promote public awareness, however with 
the demand for green networking comes manipulation of information known as 'greenwashing,' a term used to describe false environmental-friendly products, because it is difficult for a person to verify the authenticity of a product this calls for political/governmental intervention to manage 'green business,' through policies and guidelines (Patterson, 2015). Furthermore, social media pages such as Facebook and Twitter demonstrate a company's authenticity via a verification tick on the company's profile page. Consequently, due to the rapid adaptation of social media in student's/ worker's lifestyle, the research paper is aimed to analyze the current knowledge of green networking as a tool to promote recycling from the above candidates (Khurana, 2015).

\subsubsection{Economic Impacts of Recycling}

Recycling wastes can help reduce Greenhouse Gases emissions released from industries and transportation (Carbon dioxide), furthermore, it can aide in reducing water/air pollution and minimize numbers of deaths and illnesses cause by polluted air. With the increase of population comes a challenge of food management amongst global economies, even with the use of genetically modified foods (GMOs) there is a shortage of food distribution, many nations are adopting the use of social media to raise awareness on methods of recycling food, such as the use of composts and other farming practices (William et al., 2017). A Rapid population growth is causing landfills to get fuller each year across the globe, therefore; finding space for new landfills becomes an economic challenge for countries that are highly populated (Ramy et al., 2017).

A practical solution is to implement material recovery facilities to address the overfilling landfill issue. This will help reduce air pollution from waste burning (Asmatulu, \& Asmatulu, 2011). Moreover, recycling will help in saving manufacturing energy for instance: recycling aluminum cans requires less than $95 \%$ of the initial manufacturing energy also preserves natural resources (raw materials) (Benefits 2016). Recycling will also minimize the degradation of the natural resources such as trees, water, gas and oil. Secondly, recycling is significantly becoming an important subject in educational programs. The USA and many other countries are offering recycling education in universities and schools as a mandatory or optional course (Asmatulu, \& Asmatulu, 2011).

\subsubsection{UAE Governmental Interventions towards Recycling Awareness Initiatives (Dubai)}

Dubai is a developing city that is growing rapidly with the increase of population index, buildings, and industries more wastes are generated. Dubai Municipality's target is to reduce waste by spreading awareness about recycling; it has placed practices to ensure a clean environment, and to have a sustainable community lifestyle. Dubai's residents are asked to use the closest green and black bins for recycling (Dubai Municipality 2016). Several companies in the UAE have started recycling awareness campaigns, such as HP computers collaborated with 'Enviroserve' to develop the: "Touch the Green" campaign, this initiative aimed to inspire and motivate the local population to recycle their unneeded e-wastes (computers...) (Acharya 2012). 
1.1.3 Rationality for the use of Environmental Organizations as Case Studies

Firstly, Emirates Environmental Group (EEG) was chosen as a case study because they have many various recyclable items (cans, bottles, paper...) collection campaigns which engage students at different educational levels, it is a good example to see how organizations use green networking to change student's behavior towards recycling (EEG 2016).

Secondly, Provectus Middle East is a company that upholds principles of "Corporate Responsibility (CR), Social Responsibility (SR), and Corporate Social Responsibility (CSR)." The rationale for using Provectus in this paper is to provide an insight on other types of recycling (food, water) and how green networking can change individual's responses towards food and water management, moreover, Provectus is a company that works with both high school and university students, therefore, the data provided in the questioner analysis can provide interesting statistical information (P r o v e c t u s 2012).

\subsubsection{Example of Green Networking for Recycling Awareness}

Many environmental programs are starting to use social media pages as an effective tool to raise environmental awareness such as recycling, climate change, sustainability etc. The Green Ninja Project is an educational program, which focuses on teaching the young generation about sustainable development, it addresses topics like the science of climate change and familiarizes students with innovative techniques and tools to improve their sustainability lifestyle. As part of the Green Ninja educational and awareness program it uses green networking as a tool to attract students; for example, it uses YouTube as a way to share and exchange climate change awareness videos (Cordero 2012).

\section{Methodology}

For the data compilation a survey consisting of 20 questions was distributed among the students, the questioner concentrated on 5 demographics, which are: gender, age, academic level (grade level), program of study (science/ art major) and 4 academic systems (British, Arabic, Canadian, American). Moreover, the survey will derive the nature of the student's recycling lifestyle and their daily social media usage patterns, it will further illustrate their current exiting knowledge on the topic while providing their opinion on which social media platform they find most effective for green networking. Additionally, the questioner will analyze the link between the above demographics, for instance the student responses will show the difference/ similarities from different grade levels versus type of academic curriculums. In order to reduce thesis bias, the 2 environmental companies selected centre on recycling awareness for business corporations, communities and academic institutions, these 2 companies also provide a wide range of recyclables (paper, plastic, glass, food, water, cans...). The survey focuses on 8 main questions that demonstrates the types of brand awareness tools used, type of social media pages they find most effective to promote recycling for students, which items are recycled the most by students and to show the evolution of green networking over the years.

The methodologies for data collection were from: (1) physical survey; questioner handouts [institutional visits across the Emirate of Dubai] (2) online survey [Survey Monkey], (3) 


\section{Macrothink}

Environmental Management and Sustainable Development

ISSN 2164-7682

2018, Vol. 7, No. 2

physical interviews [environmental organizations visits] and (4) online interviews of environmental organizations. This collection method will provide a variety of data entry options for the volunteers, it is convenient and easily monitored to secure the accuracy of answered questions.

\section{Result \& Discussion}

\subsection{Analysis of Student's Questioner}

A twenty-question 'Green Networking \& Recycling' survey was conducted among seven hundred and seventy-seven (777) high school and university students in Dubai.

Questions 1- 5 are focused on demographics as illustrated by the table 1.

Table 1. Demographic data from student's survey

\begin{tabular}{|c|c|}
\hline Demographics & Number of Responses (\%) \\
\hline \multicolumn{2}{|l|}{ Gender } \\
\hline Male & $\mathbf{3 5 2}(45.42 \%)$ \\
\hline Female & $423(54.58 \%)$ \\
\hline \multicolumn{2}{|l|}{ Age } \\
\hline 14-16 & $151(19.48 \%)$ \\
\hline $17-20$ & $301(38.84 \%)$ \\
\hline $21-24$ & $144(18.58 \%)$ \\
\hline $25-30$ & $115(14.84 \%)$ \\
\hline $30+$ & $64(8.26 \%)$ \\
\hline \multicolumn{2}{|l|}{ Academic Level } \\
\hline High School Grade 10 & $57(7.36 \%)$ \\
\hline High School Grade 11 & $47(6.07 \%)$ \\
\hline High School Grade 12 & $206(26.61 \%)$ \\
\hline Undergrad & $261(33.72 \%)$ \\
\hline Postgrad & $203(26.33 \%)$ \\
\hline \multicolumn{2}{|l|}{ Program of Study } \\
\hline Art Student & $206(26.68 \%)$ \\
\hline Science Student & $314(40.67 \%)$ \\
\hline Both & $252(32.64 \%)$ \\
\hline \multicolumn{2}{|l|}{ Academic System } \\
\hline British & $\mathbf{1 0 9}(14.08 \%)$ \\
\hline Canadian & $152(19.64 \%)$ \\
\hline American & $\mathbf{3 6 3}(46.90 \%)$ \\
\hline Arabic & $\mathbf{1 5 0}(19.38 \%)$ \\
\hline
\end{tabular}

The above table shows the number of student's responses (\%) based on the 5 selected demographic data provided in the survey. 


\subsubsection{Student's Responses to: Green Media for Recycling Purposes}

Generally speaking, a good number of 460 students from the total 777 answered survey question \#12 in the positive, confirming that they are aware of the concept 'green networking for recycling purposes'; furthermore, among those 460 students $42.79 \%$ were females and $61.36 \%$ were males. This result shows that the male population are more aware of the concept, even though in the original total of 777 students there are more females than male participants as shown in table 1. Also, when comparing the level of awareness to the academic systems: $222(61.16 \%)$ of the American educational systems said that they're aware from both set of students, 72 British high school students (66.06\%) also said 'yes', the 82 Canadian university students (53.95\%) are aware and the 82 Arabic high school students (54.67\%) also confirmed awareness. From a total of 768 students, when asked if their institution promotes recycling through green networking, $51.56 \%$ said 'yes' while $48.44 \%$ replied 'no'.

\subsubsection{Student's Response to: Recycling Motivation Status}

It is well known that social media plays a huge role in influencing student's behaviour both academically and in their daily lifestyle, thus it is important to understand which social media platforms are most influential in raising awareness and why so. (Sandra et al., 2016) Once again from a total of 777 students, 772 answered survey questions \#17/18 referring to their 'recycling motivation status' the responses were: 562 (72.80\%) said 'yes' they are motivated to recycle and $210(27.20 \%)$ said they are not motivated to recycle. Furthermore, when compared to the type of study program, 227 science students $(72.52 \%)$ said 'yes' and the remaining $86(27.48 \%)$ said 'no' and lastly, the students who study both art and science, 191 (76.71\%) said 'yes and the remaining 58 (23.29\%) said 'no'.

These are some reasons why students lack motivation: from the 777 students 73 answered, the most common reason for lack of motivation was 'no reason', 'I'm not interested / can't be bothered' or 'I don't recycle' 'I don't care' this was the answer of 24 different students, having no reason to be motivated shows that those students have a complaisant attitude towards recycling or towards green social media, another common reason answered by around 11 students 'I don't know about it' or 'what is green social media?', 'the ads lack customer appeal' these are expected reason because the ads for green networking as a means for recycling is relatively new thus, other reasons are due to lifestyle choices because about 33 students responded as: 'I'm too busy', 'I'm lazy', 'outlet is too far', 'don't have recycling bins in their buildings' and 'lack of commitment'.

These are pure lifestyle choices which solely rest on the routine of the individuals, another consideration is, no access to recycling bins and also the adverts which the individuals have witnessed may have lacked inspirational information or it could be due to the social media page it was viewed on (Twitter, Snapchat...) it also depends on the type of media (picture, video...). From the above reasons, it is clear that the main inhibitors are due to attitude towards recycling, awareness level and lifestyle choices, however since $72.80 \%$ said they are motivated to recycle it is a good sign for assessing behaviour motivation. Motivational factors are closely linked to personality "individuals who held a general positive attitude about 


\section{Macrothink}

recycling were more likely to recycle if it was convenient for them to do so" (Phillipsen, 2015). These results are in adherence with the previous statement.

\subsubsection{Student's Response to: Most Effective Media Pages}

From the 6 categories of media pages, 763 out of the 777 students responded to survey questions \#18-20 on which media pages they found most effective to encourage recycling via green networking (illustrated in Fig 1 below): 278 (36.44\%) said YouTube, 266 (34.86\%) said Facebook, 130 (17.04\%) said Twitter, 219 (28.70\%) said Snapchat, 152 (19.92\%) said Websites and 305 (39.97\%) said Instagram. When asked which media pages they would like to see more recycling adverts from: 225 (29.18\%) said YouTube, 243 (31.52\%) said Facebook, 155 (20.10\%) said Twitter, 265 (34.37\%) said Snapchat, 156 (20.23\%) said Websites and $272(35.28 \%)$ said Instagram. This data present a good distribution and an insight to which social media pages students find more effective and in turn more motivational, from the statistics above the most effective page is Instagram and the least from Twitter, the reason why Instagram is the most effective could be, because it is a relatively new app, established in the year 2010 with over a 1million users, it also promotes awareness through pictures, videos, snap stories and promotes various businesses (eBizMBA, 2016), therefore there environmental awareness pages can easily promote their causes to attract a large scale of audience, using life changing images and inspirational videos to motivate individuals.

A particular reason as to why Twitter is the least effective is that: firstly it was established in the year 2006 (over 10 years ago) a relatively long period for it to remain trendy moreover, its main focus is on a 140 character word description (that could be a setback because individuals find images and videos more effective) however the 140 word character could be advantageous because it provides room for open discussion on status comments, furthermore, Twitter has introduced video, link and images, this will most probably attract more users. The second highest was YouTube this shows that the audience prefers to view video tutorials and animated adverts because it is more memorable (Patterson, 2015). 


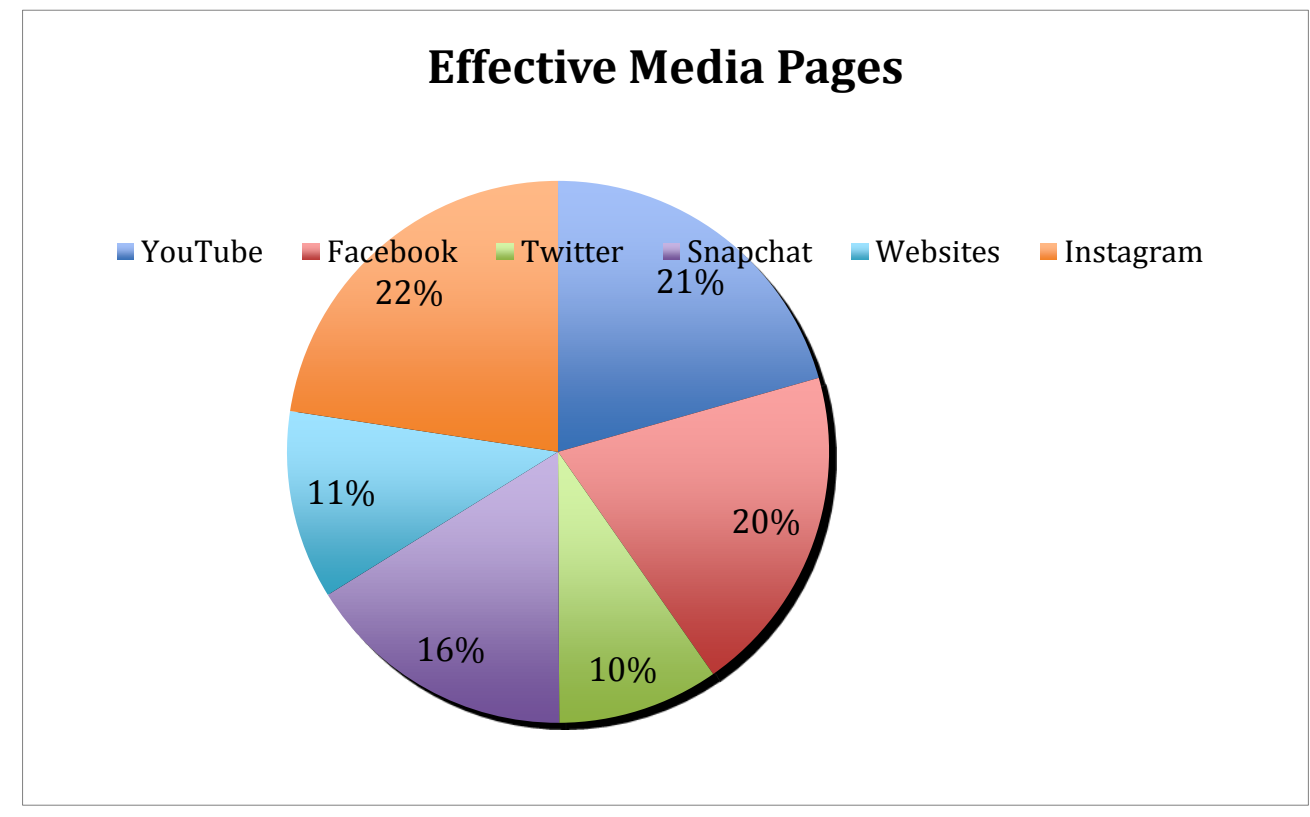

Figure 1. Effective Media Pages for Students

Figure 1 illustrates the student's responses as to which social media pages they find most effective to promote recycling awareness, based on the 6 social media pages provided in the survey.

\subsubsection{Analysis of Environmental Organizations Questioner}

The 2 organizations used in this research were asked 8 questions, the aim of this was to see the responses from an environmental organizations perspective, to see if (I) green networking is being used (II) what academic level is the target audience (III) which green network page is most effective to their cause and (IV) which group of students are most motivated to recycle. These organizations said they use green social media to promote recycling, 1 out of 2 said they work locally (UAE based) and internationally. Furthermore, they participate and organize events through the use of green networking, while addressing both high school and university students. When were asked which of the 6 categories were used, the responses are as follows:

Both organizations use Twitter and Websites to promote recycling awareness $100 \%$ of the time, while they utilize Facebook and Instagram for about $60 \%$ of their awareness campaigns, only one organization uses YouTube and none of them use Snapchat. The results show that even though the students respond undesirably to the use of Twitter, the organizations find it a successful means to professionally spread awareness. Lastly both organizations use Instagram, it is good to see that Instagram is a media tool for the organizations because as analyzed above, the students find it one of the most effective means for recycling motivation. A few reasons why these organizations do not use Snapchat are: (I) it is a new social media app and has not yet been identified as a tool for awareness promotion (II) it may be that Snapchat is time-consuming (II) the department of business development may not have the right staff to carry out the tasks. 
Additionally, when asked which social media page they found most effective, they both responded to Twitter as the most effective social media page for recycling awareness, once again the second most effective were both Facebook and Instagram, followed by Websites which came in $3^{\text {rd }}$ place, lastly neither YouTube nor Snapchat were selected as an effective green network media page. The reason could be that: (I) their marketing department do not engage in the 2 least effective categories (II) that from previous experience the organizations have found that those 2 categories provided the least responses. Finally, to complete the analysis, the organizations do participate in green networking for recycling purposes, they all have positive feedback and suggestions as to the most effective media page to use (Twitter), additionally when considering Twitter as a marketing tool the organization uses hashtag (\#), a 'green hashtag' can attract thousands for responses in a day (over 50 million green hashtags are twitted per day) (Morsella 2014). the use of hashtags may be the reason why these environmental organizations find Twitter the most effective.

The data provided shows that environmental organizations find the same green network media pages to be the most effective, this entails that when it comes to environmental awareness there is common/ collective interest in advertising recycling awareness via social media (Nazeer 2017). Lastly, according to the Department of Energy \& Environmental Protection "Social media comes into play as a way of "talking" with your target audience in order to influence and change public behaviour" (Malloy 2014), hence these companies are using green networking to encourage students to participate in recycling campaigns, this further demonstrates that green networking is one of the best ways of promoting recycling awareness among students and communities.

\section{Conclusion}

It is clear that there is a great need to ensure recycling as part of individual's lifestyles because of various economic benefits. The target audience (students and environmental organizations) help determine the attitudes of students towards recycling and the organizational approach towards green networking. This research shows the challenges and the trends of students' behaviour toward recycling through green networking, from the analysis it is clear that majority of students are aware of green networking and over $70 \%$ said they are motivated to recycle while receiving information from different social media pages. Additionally, even though each individual has their own opinion on which social media page is more effective, percentages show that majority of users prefer a media page which deals with videos, images, snap stories and discussion comments, there is a variety of options to cater to different preferences. "Social media can enhance reputation and be used to promote anything" (Kaylene et al., 2014), this proves that social media can vastly increase the success rate of sustainable initiatives, lastly, the results of the analysis show that green networking has great potential to influence student's behaviours; it is a tool that is being rapidly adopted by different environmental organizations.

\section{Acknowledgement}

We would like to acknowledge our professors, the faculty members in the Department of Environmental Health Sciences at the Canadian University Dubai. We want to thank you for 
blessing us with the gift of knowledge. Additionally, we would like to express our gratitude to the students/ organizations who participated in this study for making this research possible. Lastly, we would like to thank our two colleagues Dana Hasoneh and Reem Saadedin for their major contribution to this research.

\section{Reference}

Acharya, P. (2012, March). Domestic Solid Waste Recycling: Programs and Policies for Dubai. Domestic Solid Waste Recycling: Programs and Policies for Dubai, 38.

Asmatulu, R., \& Asmatulu, E. (2011). The importance of recycling education: A curriculum development at WSU. The Journal of Material Cycles and Waste Management, 13(2), 131-138. http://dx.doi.org/10.1007/s10163-011-0002-4

Benefits, R. (N.D). conserve-energy-future. Retrieved November 7, 2016. From http://www.conserve-energy-future.com/benefits-of-recycling.php

Cordero, E. (2012). The Use Of Social Media To Improve Climate Literacy: The green ninja project. Bulletin of the American Meteorological Society, 93(12), 1813-1814. https://doi.org/10.1175/BAMS-93-12-1813

Dannel, M. (2014). Using Social Media to Promote Recycling. Department of Energy \& Environmental Protection.

Dubai Municipality. (n.d.). Retrieved November 6, 2016, from https://www.dm.gov.ae/wps/wcm/connect/6534fcd7-90e9-473a-9f4a-934e8263712c/mycity_ english.pdf?MOD=AJPERES\&ContentCache=NONE\&CACHEID=6534fcd7-90e9-473a-9f4 a-934e8263712c

eBizMBA, 2016. Most Popular Social Networking Sites. Retrieved on 12-03-2016. From http://www.ebizmba.com/articles/social-networking-websites

EEG. (2016). About Emirates Environment Group. Retrieved November 7, 2016, from http://eeg-uae.org/site/index/?lang=en\#Home

EPA. (2016). Recycling Basiscs. Retrieved November 7, 2016. From

https://www.epa.gov/recycle/recycling-basics

Kaylene, W., Robert, P., \& Alfred, P. (2014). Green Sustainability and New Social Media. Journals of Strategic Innovation and Sustainability, 9(1/2).

Khurana, N (2015). The Impact of Social Networking Sites on the Youth. J Mass Communicat Journalism, 5, 285.

Morrison, E. E. (2012). Ethics in health administration: A practical approach for decision makers (2nd ed.). Sudbury, MA: Jones and Bartlett Publishers.

Morsella, T. (2014). The Ultimate Green Twitter Hashtag. Retrieved on 12-03-2016. From http://greeneconomypost.com/green-twitter-hashtag-17290.htm\#s

Nazeer, J. (2017). Impact of Social Media Advertisements on University Students. Arts Social 


\section{Macrothink

Sci J., 8, 290.

Patterson, M. (2015). Social Media Demographics. Retrieved on 12-03-2016. From http://sproutsocial.com/insights/new-social-media-demographics/\#all

Provectus. (2012). Energy for life. (2012). Retrieved November 07, 2016, from http://provectusme.com/corporate.asp

Ramy, S., Erasmus, E., Mi, K., Andrew, B., \& Abir, A. (2017). Environmental and health impacts of using food waste as animal feed: a comparative analysis of food waste management options. Journal of Cleaner Production, 140. http://dx.doi.org/10.1016/j.jclepro.2016.05.049

Sandra, O., \& Ismail, N. (2016). The Impact Of Social Media On Students' Academic Performance- A Case Of Malaysia Tertiary Institution. International Journal of Education, Learning and Training, 1(1).

Technopedia. (2016). Green Networking. Retrieved on 12-03-2016. From https://www.techopedia.com/definition/14755/green-networking

William, Y., Sally, R., Cheryl, R., \& Ralf, B. (2017) Can social media be a tool for reducing consumers' food waste? A behaviour change experiment by a UK retailer. Resources, Conservation and Recycling, 117, 195-203. http://dx.doi.org/10.1016/j.resconrec.2016.10.016 Yasmina, P. (2015). Factors Influencing Students' Intention to Recycle. University of Twente. Retrieved on 24-02-2018. From http://essay.utwente.nl/66693/1/Philippsen_MA_BMS.pdf

\section{Copyright Disclaimer}

Copyright for this article is retained by the author(s), with first publication rights granted to the journal.

This is an open-access article distributed under the terms and conditions of the Creative Commons Attribution license (http://creativecommons.org/licenses/by/3.0/). 